\title{
Patterns of pituitary dysfunction three months or more after traumatic brain injury
}

Nassar Taha Yaseen, Fateh A. Al-Khaqani, Abbas Ali Mansour

Department of Medicine, Basrah College of Medicine, Faiha Specialized Diabetes, Endocrine and Metabolism Center, Basrah, Iraq

\begin{tabular}{|c|}
\hline Access this article online \\
\hline Website: www.avicennajmed.com \\
\hline DOI: 10.4103/ajm.AJM_2_18 \\
\hline Quick Response Code: \\
\hline
\end{tabular}

\section{ABSTRACT}

Purpose: Chronic posttraumatic brain injury (TBI) pituitary dysfunction is not a newly discovered subject, it has been reported more frequently, probably due to increasing chances of exposure to its causes, mainly the road traffic accidents, sport-related injuries, falls, and injuries during wars. This study aims to estimate the frequency of pituitary dysfunction 3 months or more after head trauma and the patterns of hormonal deficiencies. Methods: A cross-sectional study was conducted between January 2016 and August 2017. Participants were patients having a history of moderate-to-severe TBI at least 3 months before enrolment. Pituitary function test was done for all patients to determine the frequency of pituitary dysfunction, the number of axes deficiencies, and which hormone is mostly affected. Statistical Package for the Social Sciences (SPSS) version 23.0 was used for univariate analysis, $P<0.05$ was considered statistically significant. Results: Out of the 28 patients involved in this study, $17(61 \%)$ had pituitary dysfunction, while $11(39 \%)$ had not. Single hormonal defect was the most prevalent abnormality in $12(43 \%)$, and the most affected hormone was the growth hormone $(\mathrm{GH})$ in 14 patients $(50 \%)$, followed by gonadal axis, thyroid stimulating hormone, and finally adrenocorticotropic hormone (ACTH), $6(21 \%), 3(11 \%)$, and 1 (4\%), respectively. Conclusion: TBI pituitary dysfunction is more prevalent than was predicted in the population studied, single hormonal defect was found to be the most prevalent abnormality, being the GH is the most affected axis, and the ACTH seems to be the least.

Key words: Growth hormone deficiency, head trauma, hypopituitarism, traumatic brain injury

\section{INTRODUCTION}

Posttraumatic brain injury (TBI) pituitary dysfunction is not a newly recognized subject, especially chronic pituitary dysfunction which has been reported with an increasing frequency, notably, due to increasing chance of exposure to its leading causes, mainly road traffic accidents (RTA) and wars. ${ }^{[1]}$

TBI is defined as "an alteration in brain function, or other evidence of brain pathology, caused by an external force." ${ }^{[2]}$

The acute phase of TBI represents the first 2 weeks after the trauma, while the chronic phase starts 3 months later. ${ }^{[3]}$

Address for correspondence: Prof. Abbas Ali Mansour,

Department of Medicine, Basrah College of Medicine,

Faiha Specialized Diabetes, Endocrine and Metabolism Center,

Basrah, Iraq.

E-mail: abbas.mansour@fdemc.iq
Most of the cases are attributed to RTA, while other major causes are those related to a variety of sport acts, mainly boxing and kickboxing. War-related head injuries also contribute to a large aspect of TBI, especially in countries suffered from recent conflicts. ${ }^{[4]}$

The vascular theory ${ }^{[5]}$ direct trauma, ${ }^{[6]}$ and the development of antipituitary antibodies ${ }^{[7]}$ are the main theories explaining post-TBI hypopituitarism.

This is an open access journal, and articles are distributed under the terms of the Creative Commons Attribution-NonCommercial-ShareAlike 4.0 License, which allows others to remix, tweak, and build upon the work non-commercially, as long as appropriate credit is given and the new creations are licensed under the identical terms.

For reprints contact: reprints@ medknow.com

Cite this article as: Yaseen NT, Al-Khaqani FA, Mansour AA. Patterns of pituitary dysfunction three months or more after traumatic brain injury. Avicenna J Med 2018;8:125-32. 
This study aimed at estimating the frequency and analyzing the patterns of pituitary dysfunction in the chronic phase of TBI.

\section{SUBJECTS AND METHODS}

This was a cross-sectional study conducted between January 2016 and August 2017. Participants were patients having a history of previous exposure to TBI.

TBI can be classified, from severity point of view, into mild, moderate, and severe according to the severity of the functional neurological deficit and the associated structural brain injuries. Chronologically, it could be either acute or chronic, the former represents the first 2 weeks after the onset of TBI, while the chronic phase starts after the $3^{\text {rd }}$ month from the onset. ${ }^{[3]}$

Posttraumatic amnesia (PTA), which can follow TBI, is the period until the patient regain his full orientation, we have used it as a tool to measure trauma severity, prolonged amnesia for $>24 \mathrm{~h}$ indicates a severe TBI, while PTA lasting less than a day considered to be moderate. ${ }^{[8]}$

\section{Inclusion criteria}

Patients having a history of exposure to head trauma for at least 3 months before enrolment and had suffered from moderate-to-severe TBI.

\section{Exclusion criteria}

1. Mild TBI

2. TBI patients in a chronic vegetative state with low life expectancy

3. Patients with a pituitary abnormality on pituitary imaging

4. Patients who were unwilling to participate in the study

5. Patients who had not completed their investigations.

\section{Variable tested}

After informed verbal consent was taken from the patients or their next of kin, anthropometric and clinical data have been taken from each patient in the form of:

- Age

- Gender

- Duration of hospitalization

- Less than a week

- More than a week

- Site of hospitalization

- Ward

- Intensive Care Unit (ICU)

- PTA (for assessment of severity of TBI)

- Mild TBI: $\quad$ PTA $<1 \mathrm{~h}$
- Moderate TBI: PTA $<24 \mathrm{~h}$

- $\quad$ Severe TBI: PTA $>24 \mathrm{~h}$

- Type of trauma

- Blast

- Blunt

- RTA

- Type of TBI

- Nonstructural

- Structural

- Skull fractures

- Intracerebral hemorrhage (ICH).

Any patient who had no pituitary imaging after the trauma was sent for pituitary directed neuroimaging, in particular to exclude any structural pituitary abnormalities.

\section{Biochemical testing}

A detailed history and physical examination was done for all patients, looking for any signs and symptoms of endocrine disorder, then patients were given appointment to do pituitary function test on another day to do the baseline and the dynamic tests.

For each person, $10 \mathrm{ml}$ of blood were taken during the work time 8:30 am in fasting state. All samples were collected in tubes containing clot activator, except plasma adrenocorticotropic hormone (ACTH) samples were collected in ethylenediaminetetraacetic acid tube.

All samples, except insulin-like growth factor-1 (IGF-1) which was examined by ELISA (DRG), were examined in fully automated chemiluminescence immunoassay kits Cobas e411 analyzer series Roche diagnostics.

Early morning blood samples were obtained for total serum testosterone (males), estradiol (females), prolactin (PRL), luteinizing hormone ( $\mathrm{LH})$, follicle-stimulating hormone (FSH), thyroid stimulating hormone (TSH), and total serum thyroxine (TT4) or serum-free thyroxine (FT4).

For assessment of growth hormone (GH), baseline IGF-1 and $\mathrm{GH}$ were measured, then glucagon is administered intramuscularly at a dose of $1 \mathrm{mg}$; GH then measured at 2 and $3 \mathrm{~h}$. GH deficiency is diagnosed if peak $\mathrm{GH}$ level is less than $7.1 \mathrm{ng} / \mathrm{mL}$. IGF1 value less than the normal reference for age is regarded as abnormal. ${ }^{[9]}$

Baseline ACTH and cortisol were measured followed by ACTH stimulation test, in which $250 \mu \mathrm{g}$ of cosyntropin (alpha 1-24 corticotrophin) was administered intramuscularly and cortisol levels were determined immediately before and again after 30 and $60 \mathrm{~min}$, in which peak cortisol level of 
$<20 \mu \mathrm{g} / \mathrm{dL}$ is regarded as deficient, and finding of normal or low ACTH (normal value $=10-60 \mathrm{pg} / \mathrm{mL}$ ) indicate a pituitary-adrenal axis dysfunction. ${ }^{[10]}$

Central hypothyroidism diagnosis was considered by the finding of low fT4 (normal value $=0.93-1.7 \mathrm{ng} / \mathrm{dL}$ ) or low TT4 (normal value $=5.1-14.1 \mu \mathrm{g} / \mathrm{dL}$ ) concentrations associated with low/normal TSH levels (normal value $=0.27-4.2 \mu \mathrm{IU} / \mathrm{ml}){ }^{[11]}$

Hypogonadotropic hypogonadism ( $\mathrm{HH})$ in males was diagnosed by low or low-normal FSH level and low or low-normal LH level together with low testosterone level, ${ }^{[12]}$ with cutoff value of testosterone $300 \mathrm{ng} / \mathrm{dL}$ [10-40 nmol/L], and for FSH (1-13 mIU/mL) and for LH (1-9 mIU/mL). While in females, low morning estradiol levels (normal values $=15-300 \mathrm{pg} / \mathrm{mL}$ ) in the setting of normal or low gonadotropins are diagnostic of $\mathrm{HH}(\mathrm{FSH}=2-12 \mathrm{mIU} / \mathrm{mL}$ [follicular], $20-80 \mathrm{mIU} / \mathrm{mL}$ [midcycle], and $0.5-18 \mathrm{mIU} / \mathrm{mL}$ [luteal]).

\section{RESULTS}

The vast majority of the patients who have been excluded from the study were because they had mild TBI. Some other patients had not completed their investigations for a reason or another, while others had some reluctance to participate. The remainder were only 28 patients who have been involved.

Table 1 shows the general characteristics of the patients involved in this study: from those 28 patients, 20 (71\%) were male and $8(29 \%)$ were female. The age distribution at the time of the study was as follows: patients aged $<18$ years old were 6 (21\%), 18-44 years old were 18 (64\%), and those aged $>44$ years were $4(14 \%)$ with a mean age of $29.6 \pm 2.7$ years, while the distribution at the onset of the accidents was 12 (43\%), 14 (50\%), 2 (7\%) for age groups $<18,18-44$, and 45 years old and above, respectively, with the mean age $22.5 \pm 2.5$ years.

RTA was responsible for TBI in 20 patients (71\%), while blast and blunt injuries were the causes in 4 (14\%) for each. Twenty-five patients ( $89 \%$ ) had head trauma without structural injury, while only three patients (11\%) had suffered from structural damage, from them, 2 (7\%) had skull fracture and 1 (4\%) had ICH.

Eight patients (29\%) had severe TBI with loss of consciousness of at least $1 \mathrm{~h}$ or a PTA for at least $24 \mathrm{~h}$ after the accident, while 20 (71\%) had not. Eight (29\%) were admitted to the ICU and 20 (71\%) to the ward.

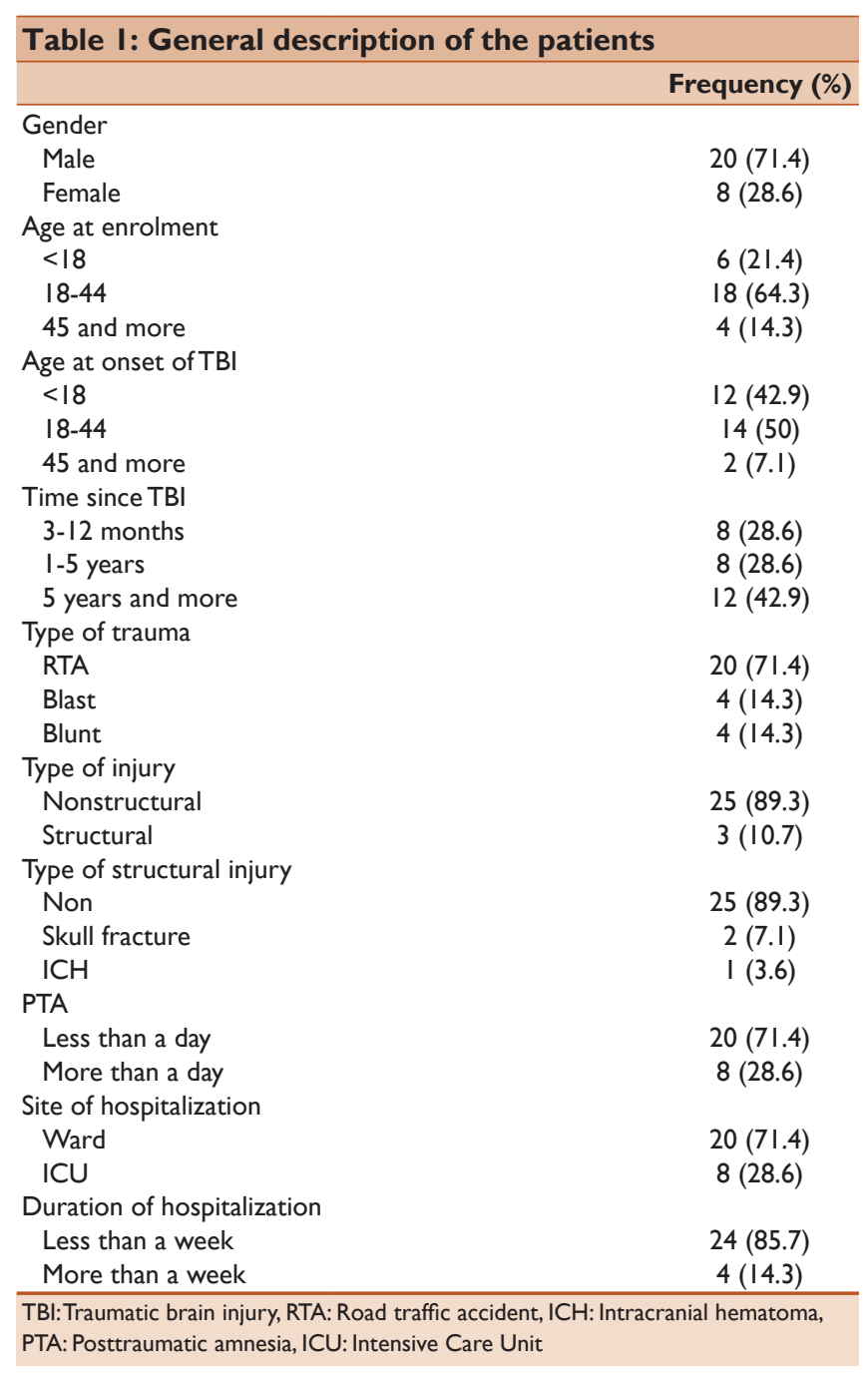

Four patients (14\%) had stayed in the hospital for more than a week and $24(86 \%)$ less than a week. There were eight patients $(29 \%)$ investigated within the $1^{\text {st }}$ year after the accident, another eight (29\%) after 1 year, and $12(43 \%)$ after the $5^{\text {th }}$ year with mean time of $86 \pm 21$ months $(7 \pm 1.8$ years $)$.

In Table 2, we had analyzed the factors affecting the development of pituitary dysfunction after TBI.

Seventeen patients (61\%) had developed pituitary dysfunction after exposure to head trauma, while 11 (39\%) had not [Figure 1]. There was no significant difference between males and females in the development of pituitary dysfunction, 12 (60\%) and 5 (62\%), respectively [Figure 2].

Interestingly, the more the duration after the onset of TBI, the more the likelihood to have a pituitary dysfunction, 3 (38\%), $5(63 \%)$, and $9(75 \%)$, respectively, for the groups of less than a year, 1 year to 5 years, and those with $>5$ years past the trauma, with mean duration of $94 \pm 25.5$ months 
( $7 \pm 2$ years) for patients with pituitary dysfunction versus $75 \pm 36.3$ months ( $6 \pm 3$ years) for the others [Figure 3].

Patients exposed to RTA and blast injuries were more prone to have pituitary problems, $13(65 \%)$ and $3(75 \%)$, respectively, in comparison to blunt trauma 1 (25\%).

All the three patients who had suffered from structural head injuries and they developed pituitary dysfunction, while exposure to a TBI without structural injuries had modest effect: 14 (56\%) affected versus 11 (44\%) had normal pituitary function.

The most affected factor in the development of pituitary dysfunction was the conscious level at time of trauma, none of the patient who had not lost their consciousness for more than an hour at the onset of the accident nor lost their memory for more than a day, had developed pituitary defect, while the 17 patients (85\%) who had lost their consciousness or memory had developed some sort of pituitary dysfunction.

The second significant affected factor was the site of hospitalization, all the eight patients who had been admitted to the ICU they developed pituitary defect, while patients admitted to the ward showed equivocal results: nine patients (45\%) versus 11 (55\%) for pituitary dysfunction and normal function, respectively.

The more the duration of hospitalization, the more the likelihood of having some sort of pituitary dysfunction in the future: all the four patients who had been admitted more than a week developed some sort of pituitary dysfunction, while only 13 patients (54\%) who were admitted less than a week developed pituitary dysfunction and 11 (45\%) had not.

Table 3 shows that the most affected hormone by head trauma was the GH in 14 patients (50\%), followed by the gonadal axis, TSH, and finally ACTH, 6 (21\%), 3 (11\%), and 1 (4\%), respectively [Figure 4].

In Table 4, we can see that a single hormonal defect was the most prevalent abnormality in $12(43 \%)$, followed by two-axis defect in $2(14 \%)$ and only one patient (4\%) had suffered from four axes deficiencies, while there has been no one diagnosed with three lines defect [Figure 5].

Further analysis of these findings can be shown in Table 5. all the five females who developed pituitary dysfunction had only one line defect, while 7 males (58\%) had one defect, $4(33 \%)$, and $1(8.3 \%)$ had two and four defects, respectively.

\begin{tabular}{|c|c|c|c|}
\hline & Yes, $n$ (\%) & No, $n$ (\%) & $P$ \\
\hline Total & $17(60.7)$ & II (39.3) & \\
\hline \multicolumn{4}{|l|}{ Gender } \\
\hline Male & $12(60)$ & $8(40)$ & 0.903 \\
\hline Female & $5(62.5)$ & $3(37.5)$ & \\
\hline \multicolumn{4}{|l|}{ Age at enrolment } \\
\hline$<18$ & $3(50)$ & $3(50)$ & 0.729 \\
\hline $18-44$ & II (6I.I) & 7 (38.9) & \\
\hline 45 and more & $3(75)$ & I (25) & \\
\hline \multicolumn{4}{|l|}{ Age at onset of TBI } \\
\hline$<18$ & $7(58.3)$ & $5(4 I .7)$ & 0.905 \\
\hline $18-44$ & $9(64.3)$ & $5(35.7)$ & \\
\hline 45 and more & I (50) & I (50) & \\
\hline \multicolumn{4}{|l|}{ Time since TBI } \\
\hline 3-12 months & $3(37.5)$ & $5(62.5)$ & 0.241 \\
\hline $\mathrm{I}-5$ years & $5(62.5)$ & $3(37.5)$ & \\
\hline 5 years and more & $9(75)$ & $3(25)$ & \\
\hline \multicolumn{4}{|l|}{ Type of trauma } \\
\hline RTA & $13(65)$ & $7(35)$ & 0.268 \\
\hline Blast & $3(75)$ & I (25) & \\
\hline Blunt & I (25) & $3(75)$ & \\
\hline \multicolumn{4}{|l|}{ Type of injury } \\
\hline Nonstructural & $14(56)$ & II (44) & 0.140 \\
\hline Structural & $3(100)$ & 0 & \\
\hline \multicolumn{4}{|c|}{ Type of structural injury } \\
\hline Non & $14(56)$ & II (44) & 0.337 \\
\hline Skull fracture & $2(100)$ & 0 & \\
\hline $\mathrm{ICH}$ & $\mathrm{I}(100)$ & 0 & \\
\hline \multicolumn{4}{|l|}{ PTA } \\
\hline Less than a day & $17(85)$ & $3(15)$ & 0.000 \\
\hline More than a day & 0 & $8(100)$ & \\
\hline \multicolumn{4}{|l|}{ Site of hospitalization } \\
\hline Ward & $9(45)$ & II (55) & 0.008 \\
\hline ICU & $8(100)$ & 0 & \\
\hline \multicolumn{4}{|c|}{ Duration of hospitalization } \\
\hline Less than a week & $13(54.2)$ & II (45.8) & 0.116 \\
\hline More than a week & $4(100)$ & 0 & \\
\hline
\end{tabular}

\begin{tabular}{lc}
\hline Table 3: Frequency of each axis deficiency & \\
\hline GH deficiency & Frequency (\%) \\
LH, FSH deficiency & $14(50)$ \\
TSH deficiency & $6(2 \mathrm{I})$ \\
ACTH deficiency & $3(1 \mathrm{I})$ \\
\hline
\end{tabular}

GH: Growth hormone, LH: Luteinizing hormone, FSH: Follicle-stimulating hormone, TSH:Thyroid-stimulating hormone, ACTH:Adrenocorticotropic hormone

On the other side, exposure to TBI at early onset in life will give more chance to developed more hormonal deficiencies. In addition, patients who had exposed to TBI for $>5$ years are more prone to have multiple defects, mean age for four hormonal defect was 21 years, two defects $26 \pm 4.8$ years, and $23 \pm 4$ years for the single defect.

A significant finding in our study is that blast and blunt trauma were always associated with more than one defect, for the blast injuries: Two (67\%) had two defects and one (33\%) has four defects, while for blunt trauma, only one 


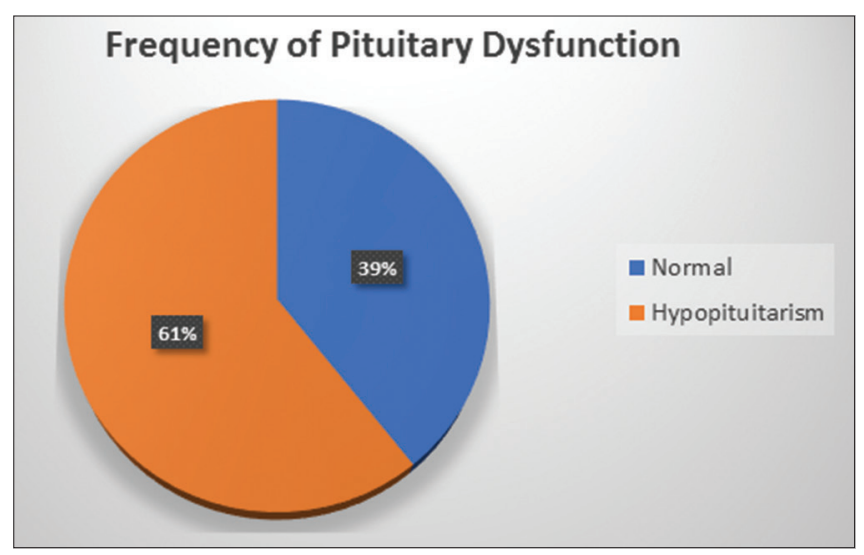

Figure 1: Frequency of pituitary dysfunction after traumatic brain injury

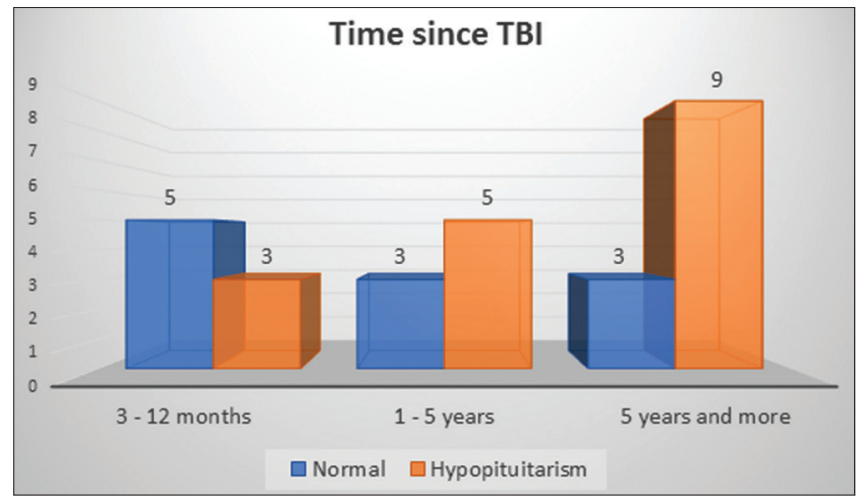

Figure 3: Frequency of pituitary dysfunction with time since traumatic brain injury

patient had two defects. In contrast to RTA where most of the patient, 12 (92\%) had only one defect and 1 patient had two defects. This finding was also noticed in a significant manner with patients suffered from TBI that was associated with structural head injury: none with single-axis defect, 2 (66\%) with two lines, and 1 (33\%) with four lines defect, while traumas without structural injuries were mostly accompanied by single hormone defect in $12(86 \%)$ and 2 (14\%) for two axes defects.

Patients who had not been admitted to the ICU were more likely to have one hormone defect in comparison with patients admitted to the ICU, for patients with no ICU admission: Eight (89\%) with single defect and 1 (11\%) with two defects and none with more than two defects, while for ICU patients: 4 (50\%), 3 (38\%), and 2 (13\%) for one, two, and four defects, respectively.

This was also true in a statistically significant manner for patients admitted for less than a week in comparison with those admitted for more than a week, where 11 patients (85\%) who had stayed in the hospital for less than a week, developed single-line defect and $2(15 \%)$ developed two lines defect, whereas 1 patient (25\%), $2(50 \%)$, and 1 (25\%) had developed

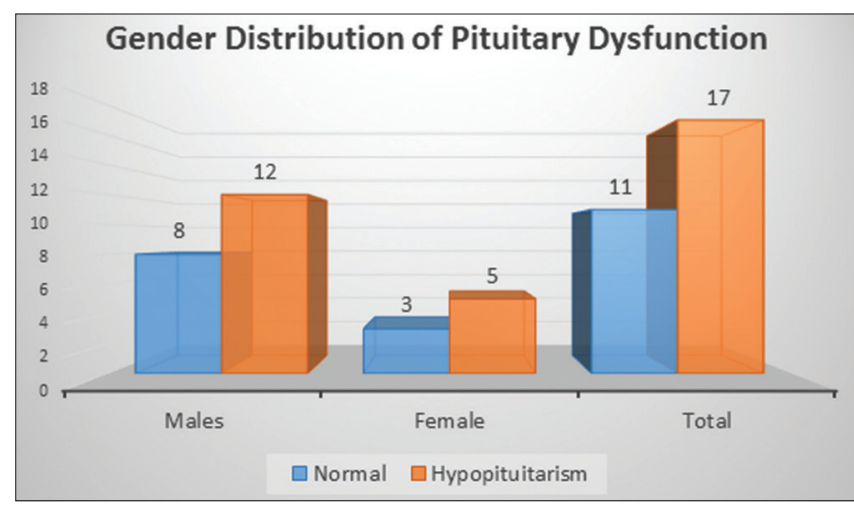

Figure 2: Gender distribution of pituitary dysfunction after traumatic brain injury

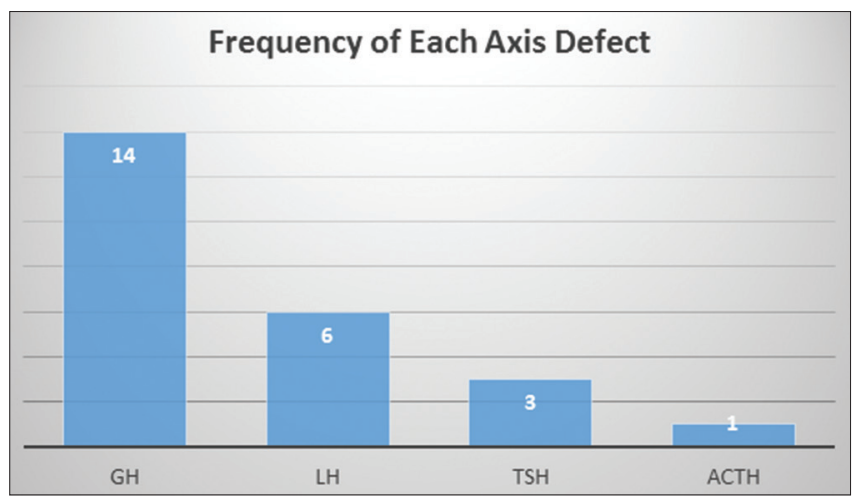

Figure 4: Frequency of each axis deficiency after traumatic brain injury

one, two, and four lines defect, respectively, when the period of admission was more than a week.

Notably, type of structural injury has no effect in determining the number of axes defect.

\section{DISCUSSION}

The high proportion of males in relation to females could be attributed to that the opportunity for exposure to an accident would be naturally more in males, especially in an oriental society. This also can be true for the explanation for being the RTA is the most common cause of TBI in our patients.

About $60 \%$ of our patients had developed some sort of pituitary dysfunction; this observation was a little bit higher than the results of similar studies that were ranging from $15 \%$ to $56 \%$.

Schneider et al. have found in their study that at least $56 \%$ of their patients would have some degree of pituitary dysfunction following TBI, ${ }^{[13]}$ while the results obtained from Leal-Cerro et al. was $24 \cdot 7 \%{ }^{[14]}$

Some studies found a percentage as low as $5.4 \%$ as Kokshoorn et al. had found in their study. ${ }^{[15]}$ 


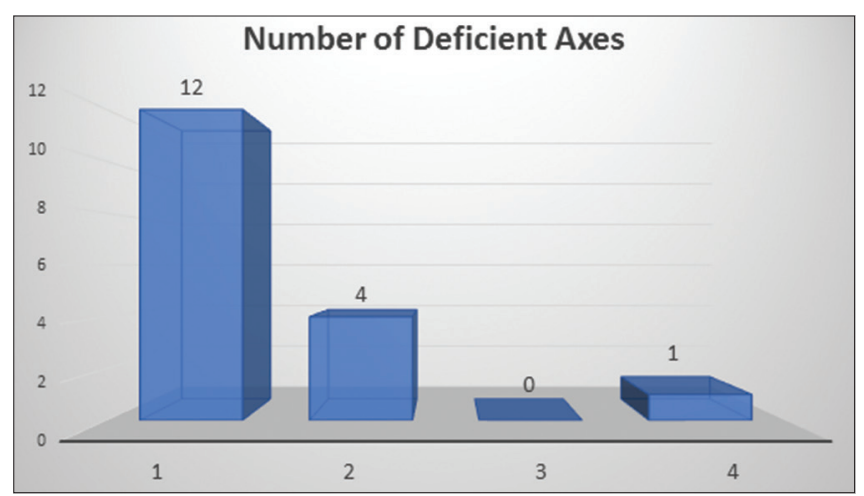

Figure 5: Number of hormonal deficiencies after traumatic brain injury

Whether those patients were having those abnormalities before the accident or later on cannot be differentiated biochemically, however, if so, it must be symptomatically noticed by the patient before the insult. ${ }^{[16]}$

In this study, statistical analysis failed to find a significant effect of gender on the possibility of having pituitary problems following TBI, a common finding that was also observed by most investigators like Aimaretti et al., Agha et al., and Tanriverdi et al. in their studies, ${ }^{[17-19]}$ however, this is in contrast to the finding of Popovic et al., who found a positive relation in males ${ }^{[20]}$ and Klose et al., who found a positive relation to females. ${ }^{[21]}$

Although we did not find a positive relationship between pituitary dysfunction and the age at which the accident had happened, as some authors have notices like Agha et al., Bondanelli et al., and Schneider et al., who found a positive relationship with older age. ${ }^{[18,22,23]}$

However, some authors had found some kind of gender-wise relationships, as Sara Preiss when she found a positive association in older females only. ${ }^{[24]}$ Moreover, Popovic who found a positive relation with older males, ${ }^{[20]}$ while Schneider et al. found a positive relationship only to $\mathrm{GH}$ in older patients. ${ }^{[13]}$

Some authors had mentioned the effect of time lapse after TBI and the presence of pituitary dysfunction, as Bondanelli et al. ${ }^{[22]}$ and Popovic, who had found an increased possibility of having some sort of pituitary impairment as more time has passed after the trauma, ${ }^{[20]}$ the same finding we have seen in our study, while Schneider et al. ${ }^{[25]}$ and Ghigo et al. ${ }^{[26]}$ had not found a significant association.

One of the explanations for this finding is the development of antipituitary antibodies as a consequence of exposure to TBI. ${ }^{[7]}$

\begin{tabular}{lc}
\hline Table 4: Number of deficient axes & \\
\hline Number of deficiencies & Frequency (\%) \\
\hline I & $12(42.9)$ \\
2 & $4(14.3)$ \\
3 & $0(0.0)$ \\
4 & $I(3.6)$ \\
\hline
\end{tabular}

Table 5: Number of dificient axes

\begin{tabular}{|c|c|c|c|c|}
\hline & \multicolumn{3}{|c|}{ Number of deficient axes } & \multirow[t]{2}{*}{$\mathbf{P}$} \\
\hline & $\mathrm{I}, \mathrm{n}(\%)$ & $2, n(\%)$ & $4, n(\%)$ & \\
\hline Total & $12(70.6)$ & $4(23.5)$ & I (8.3) & \\
\hline \multicolumn{5}{|l|}{ Gender } \\
\hline Male & $7(58.3)$ & $4(33.3)$ & I (8.3) & 0.229 \\
\hline Female & $5(100)$ & 0 & 0 & \\
\hline \multicolumn{5}{|l|}{ Age at enrolment } \\
\hline$<18$ & $3(100)$ & 0 & 0 & 0.756 \\
\hline $18-44$ & 7 (63.6) & $3(27.3)$ & I (9.I) & \\
\hline 45 and more & $2(66.7)$ & I (33.3) & 0 & \\
\hline \multicolumn{5}{|l|}{ Age at onset of TBI } \\
\hline$<18$ & $5(7 \mathrm{l} .4)$ & I (I4.3) & I (I4.3) & 0.657 \\
\hline $18-44$ & $5(66.7)$ & $3(33.3)$ & 0 & \\
\hline 45 and more & I $(100)$ & 0 & 0 & \\
\hline \multicolumn{5}{|l|}{ Time since TBI } \\
\hline 3-12 months & $2(66.7)$ & I (33.3) & 0 & 0.889 \\
\hline I-5 years & $4(80)$ & I (20) & 0 & \\
\hline 5 years and more & $6(66.7)$ & $2(22.2)$ & I (II.I) & \\
\hline \multicolumn{5}{|l|}{ Type of trauma } \\
\hline RTA & $12(92.3)$ & I (7.7) & 0 & 0.006 \\
\hline Blast & 0 & $2(66.7)$ & I (33.3) & \\
\hline Blunt & 0 & I (100) & 0 & \\
\hline \multicolumn{5}{|l|}{ Type of injury } \\
\hline Nonstructural & $12(85.7)$ & $2(14.3)$ & 0 & 0.006 \\
\hline Structural & 0 & $2(66.7)$ & I (33.3) & \\
\hline \multicolumn{5}{|c|}{ Type of structural injury } \\
\hline Non & $12(85.7)$ & $2(14.3)$ & 0 & 0.386 \\
\hline Skull fracture & 0 & I (50) & I (50) & \\
\hline $\mathrm{ICH}$ & 0 & I (I00) & 0 & \\
\hline \multicolumn{5}{|l|}{ PTA } \\
\hline Less than a day & NA (NA) & NA (NA) & NA (NA) & NA \\
\hline More than a day & NA (NA) & NA (NA) & NA (NA) & \\
\hline \multicolumn{5}{|l|}{ Site of hospitalization } \\
\hline Ward & $8(88.9)$ & I (II.I) & 0 & 0.193 \\
\hline $\mathrm{ICU}$ & $4(50)$ & $3(37.5)$ & I (I2.5) & \\
\hline \multicolumn{5}{|c|}{ Duration of hospitalization } \\
\hline Less than a week & II (84.6) & $2(15.4)$ & 0 & 0.042 \\
\hline More than a week & I (25) & $2(50)$ & I (25) & \\
\hline
\end{tabular}

As we have found that blast injuries were associated with more prevalence of pituitary dysfunction, as Baxte et al. had found that blast injuries were responsible for $>60 \%$ of pituitary dysfunction versus $<3 \%$ for nonblast injuries. ${ }^{[27]}$

The finding of the association between structural head injuries and the development of pituitary dysfunction was common among investigators, as seen by Agha et al., Schneider et al., and Kelly et al., ${ }^{[18,23,28]}$ apart from Bondanelli et al., who did not find such significant relationship. ${ }^{[22]}$ 
Yang et al. found that basal skull fracture was more significantly associated with pituitary dysfunction than ICH. ${ }^{[29]}$

The association between the conscious level following the trauma and the pituitary dysfunction has been extensively investigated, with some found a positive relationship, ${ }^{[21,22,28]}$ while others could not find such a relationship. ${ }^{[13,17,19,20,30]}$

Looking for the above factors affecting the pituitary function after trauma will give more support to the theory of antipituitary antibodies as a major contributing factor for the development of chronic pituitary dysfunction that could persist for months. ${ }^{[31]}$

Regarding the duration of hospitalization and its effect on the pituitary function, Klose and Schneider et al. found that the longer the duration of hospital stay, the more the pituitary dysfunction to develop, ${ }^{[21,32]}$ the same finding we share with them in our study.

Our finding of increased prevalence of pituitary dysfunction in ICU admission in comparison to the admission to the ward, although it has not been studied by a previous authors, can be easily explained by the fact that the more the severe TBI, the more the need for ICU stay.

Most of the investigators had found that GH deficiency is the most prevalent pituitary endocrine defect after TBI, as Tanriverdi et al., 44\%; ${ }^{[31]}$ Aimaretti et al., 18.6\%; ${ }^{[17]}$ Klose et al., 15\%; ${ }^{[21]}$ and Popovic et al., 15\%, ${ }^{[20]}$ the same result we have obtained from our study. This can be explained by the fact that the somatotrophs which are acidophilic cells are situated in the lateral aspect of the adenohypophysis, the pars lateralis, make it close contact to the boney walls of the gland and thus more vulnerable for trauma, besides, GH-secreting cells blood supply is from the long portal vessels which run in the peripheral aspect of the pituitary gland, this position put it in the hazard of being easily vulnerable to trauma.

Other authors have found the gonadal axis defect to be the most prevalent like Wachter et al., $12.7 \%$ versus $1.8 \%$ for GHD; Herrmann et al., $17 \%$ versus $8 \% ;{ }^{[33]}$ Schneider et al., $20 \%$ versus $10 \%{ }^{[13]}$ and Leal-Cerro et al., $17 \%$ versus $5.8 \%{ }^{[14]}$

Only Agha et al. have found ACTH deficiency to be the most prevalent axis defect in his study $12.7 \%$ versus 10.7 for GHD and $11.8 \%$ for gonadal axis defect, ${ }^{[18]}$ while TSH deficiency was most prevalent in the study of Berg et al., $12 \%$ versus $5 \%$ for GHD. ${ }^{[34]}$
Single hormonal defect was far more common than combined hormonal deficiencies, a common observation found by us and other authors like Lieberman et al., where he found $51 \%$ versus $17 \%$ for single versus combined deficiencies; ${ }^{[30]}$ Kopczak et al. who found $28.5 \%$ versus $4.5 \% ;{ }^{[35]}$ and Tanriverdi et al. $41 \%$ versus $10 \%$, respectively, ${ }^{[19]}$ which are in concordance with our findings.

\section{CONCLUSION}

We have discovered that chronic post TBI pituitary dysfunction is more prevalent than predicted in the population studied, single hormonal defect was found to be the most prevalent abnormality, being the $\mathrm{GH}$ is the mostly affected axis and the least hormone to be affected was the ACTH.

\section{Financial support and sponsorship}

Nil.

\section{Conflicts of interest}

There are no conflicts of interest.

\section{REFERENCES}

1. Tanriverdi F, Schneider HJ, Aimaretti G, Masel BE, Casanueva FF, Kelestimur F, et al. Pituitary dysfunction after traumatic brain injury: A clinical and pathophysiological approach. Endocr Rev 2015;36:305-42.

2. Menon DK, Schwab K, Wright DW, Maas AI; Demographics and Clinical Assessment Working Group of the International and Interagency Initiative toward Common Data Elements for Research on Traumatic Brain Injury and Psychological Health. Position statement: Definition of traumatic brain injury. Arch Phys Med Rehabil 2010;91:1637-40.

3. Teasdale G, Jennett B. Assessment of coma and impaired consciousness. A practical scale. Lancet 1974;2:81-4.

4. Consensus conference. Rehabilitation of persons with traumatic brain injury. NIH consensus development panel on rehabilitation of persons with traumatic brain injury. JAMA 1999;282:974-83.

5. Maiya B, Newcombe V, Nortje J, Bradley P, Bernard F, Chatfield D, et al. Magnetic resonance imaging changes in the pituitary gland following acute traumatic brain injury. Intensive Care Med 2008;34:468-75.

6. Salehi F, Kovacs K, Scheithauer BW, Pfeifer EA, Cusimano M. Histologic study of the human pituitary gland in acute traumatic brain injury. Brain Inj 2007;21:651-6.

7. Tanriverdi F, De Bellis A, Bizzarro A, Sinisi AA, Bellastella G, Pane E, et al. Antipituitary antibodies after traumatic brain injury: Is head trauma-induced pituitary dysfunction associated with autoimmunity? Eur J Endocrinol 2008;159:7-13.

8. Nakase-Richardson R, Sherer M, Seel RT, Hart T, Hanks R, Arango-Lasprilla JC, et al. Utility of post-traumatic amnesia in predicting 1-year productivity following traumatic brain injury: Comparison of the russell and mississippi PTA classification intervals. J Neurol Neurosurg Psychiatry 2011;82:494-9.

9. Aimaretti G, Baffoni C, DiVito L, Bellone S, Grottoli S, Maccario M, et al. Comparisons among old and new provocative tests of $\mathrm{GH}$ secretion in 178 normal adults. Eur J Endocrinol 2000;142:347-52.

10. Karaca Z, Lale A, Tanriverdi F, Kula M, Unluhizarci K, Kelestimur F, et al. The comparison of low and standard dose ACTH and glucagon stimulation tests in the evaluation of hypothalamo-pituitary-adrenal 
axis in healthy adults. Pituitary 2011;14:134-40.

11. Ferretti E, Persani L, Jaffrain-Rea ML, Giambona S, Tamburrano G, Beck-Peccoz P, et al. Evaluation of the adequacy of levothyroxine replacement therapy in patients with central hypothyroidism. J Clin Endocrinol Metab 1999;84:924-9.

12. Petak SM, Nankin HR, Spark RF, Swerdloff RS, Rodriguez-Rigau LJ; American Association of Clinical Endocrinologists, et al. American Association of Clinical Endocrinologists medical guidelines for clinical practice for the evaluation and treatment of hypogonadism in adult male patients-2002 update. Endocr Pract 2002;8:440-56.

13. Schneider HJ, Schneider M, Saller B, Petersenn S, Uhr M, Husemann B, et al. Prevalence of anterior pituitary insufficiency 3 and 12 months after traumatic brain injury. Eur J Endocrinol 2006;154:259-65.

14. Leal-Cerro A, Flores JM, Rincon M, Murillo F, Pujol M, Garcia-Pesquera F, et al. Prevalence of hypopituitarism and growth hormone deficiency in adults long-term after severe traumatic brain injury. Clin Endocrinol (Oxf) 2005;62:525-32.

15. Kokshoorn NE, Smit JW, Nieuwlaat WA, Tiemensma J, Bisschop PH, Groote Veldman R, et al. Low prevalence of hypopituitarism after traumatic brain injury: A multicenter study. Eur J Endocrinol 2011;165:225-31.

16. Masel BE, Zgaljardic DJ, Forman J. Post-traumatic hypopituitarism and fatigue. Neuropsychol Rehabil 2017;27:1071-9.

17. Aimaretti G, Ambrosio MR, Di Somma C, Gasperi M, Cannavò S, Scaroni C, et al. Residual pituitary function after brain injury-induced hypopituitarism: A prospective 12-month study. J Clin Endocrinol Metab 2005;90:6085-92.

18. Agha A, Rogers B, Sherlock M, O'Kelly P, Tormey W, Phillips J, et al. Anterior pituitary dysfunction in survivors of traumatic brain injury. J Clin Endocrinol Metab 2004;89:4929-36.

19. Tanriverdi F, Senyurek H, Unluhizarci K, Selcuklu A, Casanueva FF, Kelestimur F, et al. High risk of hypopituitarism after traumatic brain injury: A prospective investigation of anterior pituitary function in the acute phase and 12 months after trauma. J Clin Endocrinol Metab 2006;91:2105-11.

20. Popovic V, Pekic S, Pavlovic D, Maric N, Jasovic-Gasic M, Djurovic B, et al. Hypopituitarism as a consequence of traumatic brain injury (TBI) and its possible relation with cognitive disabilities and mental distress. J Endocrinol Invest 2004;27:1048-54.

21. Klose M, Juul A, Poulsgaard L, Kosteljanetz M, Brennum J, Feldt-Rasmussen U, et al. Prevalence and predictive factors of post-traumatic hypopituitarism. Clin Endocrinol (Oxf) 2007;67:193-201.

22. Bondanelli M, De Marinis L, Ambrosio MR, Monesi M, Valle D, Zatelli MC, et al. Occurrence of pituitary dysfunction following traumatic brain injury. J Neurotrauma 2004;21:685-96.

23. Schneider M, Schneider HJ, Yassouridis A, Saller B, von Rosen F,
Stalla GK, et al. Predictors of anterior pituitary insufficiency after traumatic brain injury. Clin Endocrinol (Oxf) 2008;68:206-12.

24. Preiss-Farzanegan SJ, Chapman B, Wong TM, Wu J, Bazarian JJ. The relationship between gender and postconcussion symptoms after sport-related mild traumatic brain injury. PM R 2009;1:245-53.

25. Schneider HJ, Sämann PG, Schneider M, Croce CG, Corneli G, Sievers C, et al. Pituitary imaging abnormalities in patients with and without hypopituitarism after traumatic brain injury. J Endocrinol Invest 2007;30:RC9-12.

26. Ghigo E, Masel B, Aimaretti G, Léon-Carrión J, Casanueva FF, Dominguez-Morales MR, et al. Consensus guidelines on screening for hypopituitarism following traumatic brain injury. Brain Inj 2005; 19:711-24.

27. Baxter D, Sharp DJ, Feeney C, Papadopoulou D, Ham TE, Jilka S, et al. Pituitary dysfunction after blast traumatic brain injury: The UK BIOSAP study. Ann Neurol 2013;74:527-36.

28. Kelly DF, Gonzalo IT, Cohan P, Berman N, Swerdloff R, Wang C, et al. Hypopituitarism following traumatic brain injury and aneurysmal subarachnoid hemorrhage: A preliminary report. J Neurosurg 2000;93:743-52.

29. Yang WH, Chen PC, Wang TC, Kuo TY, Cheng CY, Yang YH, et al. Endocrine dysfunction following traumatic brain injury: A 5-year follow-up nationwide-based study. Sci Rep 2016;6:32987.

30. Lieberman SA, Oberoi AL, Gilkison CR, Masel BE, Urban RJ. Prevalence of neuroendocrine dysfunction in patients recovering from traumatic brain injury. J Clin Endocrinol Metab 2001;86:2752-6.

31. Tanriverdi F, De Bellis A, Ulutabanca H, Bizzarro A, Sinisi AA, Bellastella $G$, et al. A five year prospective investigation of anterior pituitary function after traumatic brain injury: Is hypopituitarism long-term after head trauma associated with autoimmunity? J Neurotrauma 2013;30:1426-33.

32. Schneider HJ, Kreitschmann-Andermahr I, Ghigo E, Stalla GK, Agha A. Hypothalamopituitary dysfunction following traumatic brain injury and aneurysmal subarachnoid hemorrhage: A systematic review. JAMA 2007;298:1429-38.

33. Herrmann BL, Rehder J, Kahlke S, Wiedemayer H, Doerfler A, Ischebeck W, et al. Hypopituitarism following severe traumatic brain injury. Exp Clin Endocrinol Diabetes 2006;114:316-21.

34. Berg C, Oeffner A, Schumm-Draeger PM, Badorrek F, Brabant G, Gerbert B, et al. Prevalence of anterior pituitary dysfunction in patients following traumatic brain injury in a german multi-centre screening program. Exp Clin Endocrinol Diabetes 2010;118:139-44.

35. Kopczak A, Kilimann I, von Rosen F, Krewer C, Schneider HJ, Stalla GK, et al. Screening for hypopituitarism in 509 patients with traumatic brain injury or subarachnoid hemorrhage. J Neurotrauma 2014;31:99-107. 